IRA-International Journal of Technology \& Engineering ISSN 2455-4480

Proceedings of the

International Conference on Science \& Engineering for Sustainable Development (2017)

Pg. no.214-225

Published by: Institute of Research Advances https://research-advances.org/index.php/IRAJTE

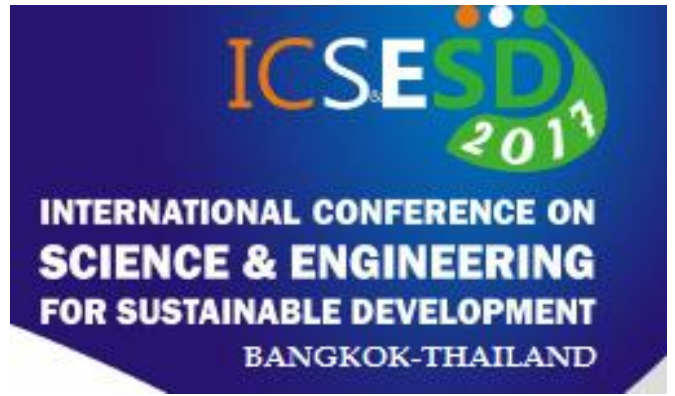

\title{
ATC using FACTS Devices in Deregulated Power Systems
}

\author{
Prakash Burade*1, Rajendra Sadafale ${ }^{2}$, Anand Satpute ${ }^{3}$ \\ 1,2,3 SANDIP INSTITUTE OF TECHNOLOGY \& RESERCH CENTER-NASHIK (MS), \\ India
}

Type of Review: Originality Check \& Peer Review under the responsibility of the Scientific Committee of the Conference and The Institution of Engineers (India). DOI: http://dx.doi.org/10.21013/jte.ICSESD201721

\begin{abstract}
How to cite this paper:
Burade, P., Sadafale, R., Satpute, A. (2017). ATC using FACTS Devices in Deregulated Power Systems. Proceedings of the International Conference on Science \& Engineering for Sustainable Development (2017), 214-225. doi: http://dx.doi.org/10.21013/ite.ICSESD201721
\end{abstract}

(C) International Conference on Science \& Engineering for Sustainable Development\& The Institution of Engineers (India).

\section{(c) EY-NC}

This work is licensed under a Creative Commons Attribution-Non Commercial 4.0 International License subject to proper citation to the publication source of the work.

Disclaimer: The conference papers as published by the Institute of Research Advances (IRA) are the views and opinions of their respective authors and are not the views or opinions of the IRA. The IRA disclaims of any harm or loss caused due to the published content to any party. 


\section{ABSTRACT}

A Repeated Power Flow with FACTS devices including ATC is used to evaluate the feasible ATC value within real and reactive power generation limits, line thermal limits, voltage limits and FACTS operation limits. An IEEE-30 bus system is used to demonstrate the effectiveness of the algorithm as an optimization tool to enhance ATC. A Genetic Algorithm technique is used for validation purposes. Introduction of FACTS devices in a right combination of location and parameters could enhance ATC and Ant Colony optimization can be efficiently used for this kind of nonlinear integer optimization.

Keywords: RPF, FACTS, Available Transfer Capability, Ga, ACO, OPF

\section{Introduction}

In recent years, power system operation faces new challenges due to deregulation and restructuring of the electricity markets. The old system known as monopoly based are substituted by a competitive marketplace. Hence the new structures of power system become more complex. These new structures have to deal with problem raised by the difficulties in building new transmission lines and the significant increase in power transactions associated to competitive electricity markets. Thus a large interconnected system has been built in order to be able to obtain a high operational efficiency and network security. In this situation, one of the possible solutions to improve the system operation is the use of flexible ac transmission technologies (FACTS).

The implementation of the FACTS devices extends the possibility that current through a line can be controlled at a reasonable cost, enabling large potential of increasing the capacity of existing lines, and use of one of the FACTS devices to enable corresponding power to flow through such lines under normal and contingency conditions.

Several studies [5, 49, 79, and130] have found that FACTS technology not only provides solutions for efficiently increasing transmission system capacity but also increases ATC, relieve congestion, improve reliability and enhances operation and control. However, it is hard to determine the optimal allocation and parameters of FACTS devices due to the complicated combinatorial optimization. Thus, attention is paid in this current work to study a technique to optimally allocate the devices to enhance ATC. The task of calculating ATC is one of main concerns in power system operation and planning. ATC is determined as a function of increase in power transfers between different systems through prescribed interfaces. Various OPF methods are detailed discussed in this paper.

In [2], Evolutionary Programming was used to determine the optimal allocation of FACTS for maximizing TTC between sources and sink area. Four types of FACTS are included in the studies; TCSC, UPFC, TCPS and SVC. The inequality constraints are power generation limit, voltage limit, line flow limit and facts operation limit. Three important aspects of FACTS to be considered throughout the optimization were the types of FACTS controller used, rated value and its location. The algorithm demonstrates the effectiveness of FACTS to improve system load ability. It did not compare the proposed method with other optimization methods to show the robustness of the proposed methods. In[136] presented a Parallel Tabu Search (PTS) based method for determining optimal allocation of FACTS devices in competitive power systems. Available Transfer Capability (ATC) was maximized with the FACTS devices. UPFC was modeled and concept of incremental load rate was used. The proposed method was compared with Simulated Annealing, GA and Tabu Search methods. It is 1.95 and 2.68 times 
faster than TS and GA respectively. It is not affected by the initial conditions and gave higher quality solutions.

In PSO technique is used to find optimal location of FACTS to achieve maximum system load ability with minimum cost of installations of FACTS. The combinations of multi-type of FACTS were considered with line thermal limit and bus voltage limit as their inequality constraints. While in only STATCOM has been used to perform the effectiveness of PSO in allocating the devices. In this paper, the STATCOM is placed to improve voltage profile, minimize power system total losses and maximize system load ability with respect to the size of it. Furthermore, no comparison has been made in showing the robustness of the method with other existing methods.

In this paper, novel method using Ant Colony Optimization technique is proposed to determine the optimal allocation of FACTS devices for maximizing the Available Transfer Capability (ATC) of power transactions between source and sink areas in the deregulated power system. The algorithm simultaneously searches the FACTS location, FACTS parameters and FACTS types. Two types of FACTS are simulated in this study namely Thyristor Controlled Series Compensator (TCSC) and Static Var Compensator (SVC). The FACTS devices to enable corresponding power to flow through such lines under normal and contingency conditions. Several studies [5] have found that FACTS technology not only provides solutions for efficiently increasing transmission system capacity but also increases ATC, relieve congestion, improve reliability and enhances operation and control. However, it is hard to determine the optimal allocation and parameters of FACTS devices due to the complicated combinatorial optimization. Thus, attention is paid in this current work to study a technique to optimally allocate the devices to enhance ATC. The task of calculating ATC is one of main concerns in power system operation and planning. ATC is determined as a function of increase in power transfers between different systems through prescribed interfaces.

\section{Mathematical Model of FACTS Devices}

TCSC: The TCSC changes the line reactance. It can be inductive or capacitive compensation respectively by modifying the line reactance. The reactance of TCSC is adjusted directly based on the reactance of the transmission line.

$$
X i j=X \text { line }+X \text { TCSC }=r \text { TCSC. Xline }
$$

Where $\mathrm{X}$ line is the reactance of the transmission line, $X$ TCSC represents the reactance contributes by TCSC and $\mathrm{r}$ TCSC represents the degree of compensation of TCSC. The working range of TCSC ( $X_{M I N}$ $\left.\sim X_{M A X}\right)$ is set between -0.7 Xline and 0.2 Xline.

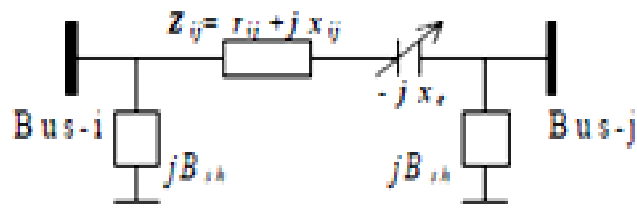

Fig.1: Equivalent Circuit of TCSC

$$
\begin{aligned}
& P_{l j}^{c}=V_{i}^{2} G_{i j}^{\prime}-V_{i} V_{j}\left(G_{i j}^{\prime} \cos \delta_{i j}+B_{i j}^{\prime} \sin \delta_{i j}\right)_{(1)} \quad Q_{l j}^{c}=-V_{i}^{2}\left(B_{i j}^{\prime}+B_{s h}\right)-V_{i} V_{j}\left[G_{i j}^{\prime} \sin \left(\delta_{i j}\right)-B_{i j}^{\prime} \cos \left(\delta_{i j}\right)\right]
\end{aligned}
$$

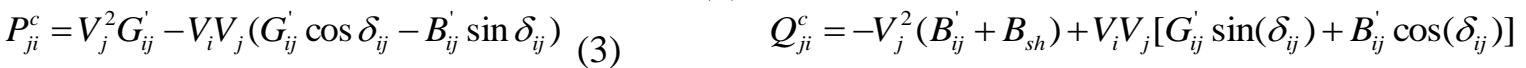




$$
P_{L k}^{c}=V_{i}^{2} G_{i j}^{\prime}+V_{j}^{2} G_{i j}^{\prime}-2 V_{i} V_{j} G_{i j}^{\prime} \cos \delta_{i j}(5) \quad G_{i j}^{\prime}=\frac{r_{i j}}{r_{i j}^{2}+\left(x_{i j}-x_{c}\right)^{2}}, B_{i j}^{\prime}=\frac{-\left(x_{i j}-x_{c}\right)}{r_{i j}^{2}+\left(x_{i j}-x_{c}\right)^{2}}
$$

The change in the line flow due to series capacitance can be represented as a line without series capacitance with power injected at the receiving and sending ends of the line as shown in Fig. 3 . The real power injections at bus- $\mathrm{i}\left(P_{i c}\right)$ and bus- $\mathrm{j}\left(P_{j c}\right)$ can be expressed, using equations

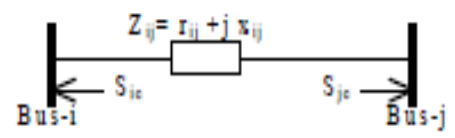

Fig. 2. Injection model of TCSC

$$
\begin{gathered}
P_{i c}=V_{i}^{2} \Delta G_{i j}-V_{i} V_{j}\left[\Delta G_{i j} \cos \delta_{i j}+\Delta B_{i j} \sin \delta_{i j}\right] \\
P_{j c}=V_{j}^{2} \Delta G_{i j}-V_{i} V_{j}\left[\Delta G_{i j} \cos \delta_{i j}-\Delta B_{i j} \sin \delta_{i j}\right] \\
Q_{i c}=-V_{i}^{2} \Delta B_{i j}-V_{i} V_{j}\left[\Delta G_{i j} \sin \delta_{i j}+B_{i j} \cos \delta_{i j}\right] \\
Q_{j c}=-V_{j}^{2} \Delta B_{i j}+V_{i} V_{j}\left[\Delta G_{i j} \sin \delta_{i j}+\Delta B_{i j} \cos \delta_{i j}\right]
\end{gathered}
$$

SVC:The SVC is a shunt connected static VAR generator or Absorber. The SVC can be used to control the reactive compensation of a system. BSVC represents the controllable susceptance of SVC. It can beoperated as inductive or capacitive compensation. In this study, it is modeled as an ideal reactive power injection at bus $i$, at where it is connected. The working range of SVC is between -100 Mvar and 100 Mvar

$$
P_{j}=0 ; \quad Q_{j}=-\left|V_{j}\right|^{2} B_{S V C}
$$

Also power mismatch are given as

$$
\begin{aligned}
{\left[\begin{array}{c}
\Delta P_{j} \\
\Delta Q_{j}
\end{array}\right] } & =\left[\begin{array}{cc}
0 & 0 \\
0 & \frac{\partial Q_{j}}{\partial B_{S V C}}
\end{array}\right]\left[\begin{array}{l}
\Delta \delta_{j} \\
\Delta B_{S V C}
\end{array}\right] \\
B_{S V C}^{(p+1)} & =B_{S V C}^{(p)}+\Delta B_{S V C}^{(p)}
\end{aligned}
$$

At the end of iteration $P$, the variable shunt susceptance is corrected as

This may further be written as

$$
B_{S V C}^{(p+1)}=B_{S V C}^{(p)}+\left(\Delta B_{S V C} / B_{S V C}\right)^{(p+1)} B_{S V C}^{(p)}
$$

The changing the susceptance represents the total SVC susceptance necessary to maintain the nodal voltage magnitude at the specified value. SVC compensation may also be computed in terms of thyristor 
firing angle. However, the additional calculation requires an iteration solution as the SVC susceptance and thyristor firing angle are non-linearly related.

The steady-state susceptance of SVC can be obtained from the relation,

$$
B_{S V C}=B_{c}-B_{T C R}=\frac{1}{X_{c} X_{l}}\left[X_{l}-\frac{X_{c}}{\Pi}\{2(\Pi-\alpha)+\sin (2 \alpha)\}\right]
$$

Where $X_{l=} \omega L$ and $X_{c}=\frac{1}{\omega c}$.

Since, $Q_{j}=-V_{j}^{2} B_{S V C}$, we can write

$$
Q_{j}=-\frac{V_{j}^{2}}{X_{c} X_{l}}\left[X_{l}-\frac{X_{c}}{\Pi}\{2(\Pi-\alpha)+\sin (2 \alpha)\}\right]
$$

(Assuming that $Q_{j}$ is the jth bus reactive power injected due to SVC installation at the jth bus).The linearized SVC equation is then given by,

$$
\left[\begin{array}{l}
\Delta P_{j} \\
\Delta Q_{j}
\end{array}\right]^{(p+1)}=\left[\begin{array}{ll}
0 & 0 \\
0 & \frac{2 V_{j}^{2}}{\Pi X_{l}}[\cos (2 \alpha)-1
\end{array}\right]^{(p+1)}\left[\begin{array}{l}
\Delta \delta_{j} \\
\Delta \alpha
\end{array}\right]^{(p+1)}
$$

$\alpha$ is the firing angle of SVC. Therefore, at the end of iteration, the variable firing angle $\alpha$ is updated by the equation by the equation.

$$
\alpha^{(p+1)}=\alpha^{(p)}+\Delta \alpha^{(p+1)}(19)
$$

The bus with which the SVC is connected (i.e. the jth bus) becomes a voltage- controlled bus where the voltage magnitude and active and reactive powers are specified along with either the SVC firing angle $(\alpha)$ or the SVC equivalent susceptance ( $B_{S V C}$ ). If $\alpha$ or $B_{S V C}$ is within limits, the specified voltage magnitude is attained and the bus remains as voltage. Controlled (PV) bus. However, is $\alpha$ or $B_{S V C}$ go beyond limits, then these variables are fixed at the violated limits and the bus becomes a pure load (PQ) bus.

\section{Problem Formulation}

The main objectives of this work is to determine the optimal location and the optimal parameter setting of the FACTS device in the power network to maximize the available power that can be transferred from a specific set of generators in a source area to loads in sink area, subject to real and reactive power generation limits, voltage limits, line thermal limits and FACTS devices operation limits.

The RPF with FACTS devices is used to evaluate the feasible ATC value of the power transactions. RPF is based on generalized search method, where successive power flow solution is performed until it reaches the maximum transfer capability. The RPF enables transfers by increasing complex load in the sink area and injected real power generation in the source area in incremental steps until any violation incurred.

Mathematically, the calculation of TTC with TCSC or SVC is installed in the network can be defined as:

$$
\operatorname{Max} F(x)=O_{A T C} \quad \text { (20)Subject to: }
$$




$$
\begin{array}{lc}
E(f, g)=0 & P G_{i}^{\min } \leq P G_{i} \leq P G_{i}^{\max } \\
Q G_{i}^{\min } \leq Q G_{i} \leq Q G_{i}^{\max } & \text { (22) } S_{i} \leq S_{i}^{\max } \\
X_{T C S C}^{\min } \leq X_{i} \leq X_{T C S C}^{\max } & \text { (24) } \quad Q_{S V C}^{\min } \leq Q_{S V C} \leq Q_{S V C}^{\max }
\end{array}
$$

Where,

$O_{A T C}$ : ATC maximized function

$E(f, g)$ : Conventional power flow equation

$P G_{i}, Q G_{i}$ : Real and reactive power generation at bus $\mathrm{i}$

$\mathrm{f}:$ The variables of FACTS devices

$\mathrm{g}$ : Operating state of the power system

$V_{i}^{\min }, V_{i}^{\max }: \quad$ Lower and upper limit of voltage magnitude at bus i

$S_{i}^{\min }, S_{i}^{\max }:$ Thermal limit of line i

$Q_{S V C}^{\min }, Q_{S V C}^{\max }$ : reactive power limit

$X_{T C S C}^{\min }, X_{T C S C}^{\max }$ : TCSC line reactance limit

For calculating TTC and ATC, the injected $P_{G i}$ at source area, and $P_{D i}$ and $Q_{D i}$ at sink area are increased in function of $\lambda$ in which;

$$
\begin{aligned}
& P_{G i}=P_{G i}^{0}\left(1+\lambda K_{G i}\right) \\
& P_{D i}=P_{D i}^{0}\left(1+\lambda K_{D i}\right) \\
& Q_{D i}=Q_{D i}^{0}\left(1+\lambda K_{D i}\right)
\end{aligned}
$$

Where $P_{G i}^{0}, P_{D i}^{0}, Q_{D i}^{0}$ are the base case injection at bus-i and $K_{G i}, K_{D i}$ are the constant used to specify the rate of changes in load as $\lambda$ varies. In order to maintain a zero balance, the incremental power losses resulting from increases in transfer power are allocated by a given formula. At PV buses, the reactive power is maintain at the base case value. However, in sink area, the reactive power demand $Q_{D i}$ is incremented accordingly to real power in order to keep a constant value of power factor. The rate of $\lambda$ change from $\lambda=0$ corresponds to no transfer (base case) to $\lambda=\lambda_{\max }$ corresponds to the largest value of transfer power that causes no limit violations. $\mathrm{PD}_{\mathrm{i}}\left(\lambda_{\max }\right)$ is the sum of load in sink area when $\lambda=\lambda_{\max }$ while $\mathrm{PoD}_{\mathrm{i}}$ refers to the sum of load when $\lambda=0$. Therefore, the sum of real power loads in sink area at the maximum power transaction in (normal or contingency case) represents the TTC value.

$$
T T C=\sum_{i=1}^{N d-S N K} P_{D i}\left(\lambda_{\max }\right)-\sum_{i=1}^{N d-S N K} P_{D i}^{0}
$$

\section{Proposed Methodology of ANT Colony Optimization}

The general algorithm ACO operators for the implementation of OPF. In the process involves initialization, state transition rule, local updating rule, fitness evaluation and global updating rule.

Step 1: Initialization; during the initialization process $n, m, t_{\max }, d_{\max }, \beta, \rho, \alpha$ and $q 0$ are specified.

Where

$n$ : no. of nodes

$m$ : no. of ants 
$t_{\text {max }}$ : maximum iteration

$d_{m a}:$ maximum distance for every ants tour

$\beta$ : parameter, which determines the relative importance of pheromone versus instance $(\beta>0)$

$\rho$ : heuristically defined coefficient $(0<\rho<1)$

$\alpha$ :pheromone decay parameter $(0<\alpha<1)$

$q_{0}$ : parameter of the algorithm $(0<q 0<1)$

$\tau_{0} \quad$ : initial pheromone level

Every parameter requires to be set for limiting the search range in order to avoid large computation time.

$d$ max can be calculated using the following formula:

$\mathrm{d}_{\max }=\max \left[\sum_{i=1}^{n-1} d_{i}\right]$

Where:

$r: \quad$ current node

$u$ : unvisited node

$\mathrm{d}: \quad$ distance between two nodes

Step 2: Generate first node randomly; the first node will be selected by generating a random number according to a uniform distribution, ranging from 1 to $n$.

Step 3: Apply state transition rule; in this step the ant located at node $r$ (current node) will choose the nodes $s$ (next node) based on the following rule.

$$
s=\left\{\begin{array}{l}
\arg \max _{u \in}\left\{\left\{(r, u) \cdot\left[\eta(r, u)^{\beta}\right]\right\}, \text { if } q \leq q_{0}(\exp \text { loration })\right. \\
s, \text { otherwise (biased } \exp \text { loration })
\end{array}\right\}
$$

Where:

$q:$ random number uniformly distributed in $[0 \ldots 1]$

$S$ : random variable selected according to the probability distribution given in equation (31)

The probability for an ant $k$ at node $r$ to choose the next node $s$, is calculated using the following equation

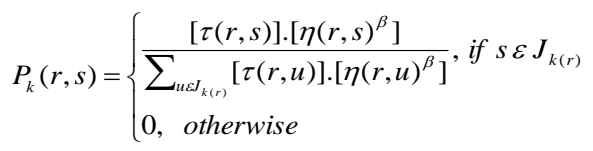

Where

$\tau \quad:$ Pheromone

$J_{k(r)}$ : set of nodes that remain to be visited by ant $k$ positioned on node (to make the solution feasible)

$\eta \quad: 1 / \delta$, is the inverse of the distance $\tau(r, s)$

Ants that have the highest fitness are chosen as "selected ants" ( $m$ nodes) and path visited by them are chosen for neighborhood search.

Step 4: Apply local updating rule; while constructing a solution of UPFC optimization, ants visit edges and change their pheromone level by applying the local updating rule of equation 33

$$
\tau(r, s) \leftarrow(1-\rho) \tau(r, s)+\rho . \Delta \tau(r, s)
$$

$\rho \quad$ : heuristically defined coefficient $(0<\rho<1)$

$\Delta \tau(r, s)=\tau_{0}$ 
Step 5: Determine tuned parameters; two variables $(\mathrm{x} 1, \mathrm{x} 2)$ required to represent the UPFC parameters (i.e. UPFC voltage constant, Vs and angle, $\phi_{s}$ ) and are selected within the specified ranges from RSA method.

Step 6: Fitness evaluation; it is performed after all ants have completed their tours. In this step, the control variable is computed using the following $\mathrm{e}$

$x=\frac{d}{d_{\max }} \times x_{\max }$

where:

$d$ : distance for every ants tour

$x_{\max }:$ maximum $\mathrm{x}$

The values of $x$ will be assigned for UPFC parameters. The fitness is computed by performing ac load flow program. This program is called repeatedly into the ACO main program for the whole process.

Step 7: Apply global updating rule; to simplify the problem, this step is applied to edges belonging to the best ant tour which give the best fitness among all ants. The pheromone level is updated by applying the global updating rule in equation 35

$\tau(r, s) \leftarrow(1-\alpha) \tau(r, s)+\alpha \cdot \Delta \tau(r, s)$

Where,

$\Delta(r, s)=\left\{\begin{array}{l}\left(L_{g b}\right)^{-1}, \text { if }(r, s) \varepsilon \text { global }- \text { best tour } \\ 0, \text { otherwise }\end{array}\right.$

$\left(L_{g b}\right)$ : The length of the globally best tour from the beginning of the trial

Step 8: End condition; the algorithms stop the iteration when a maximum number of iterations have been performed otherwise, repeat step 3. Every tour that was visited by ants should be evaluated. If a better path is discovered in the process, it will be kept for next reference. The best path selected between all iterations engages the optimal scheduling solution to UPFC optimal parameters problem.

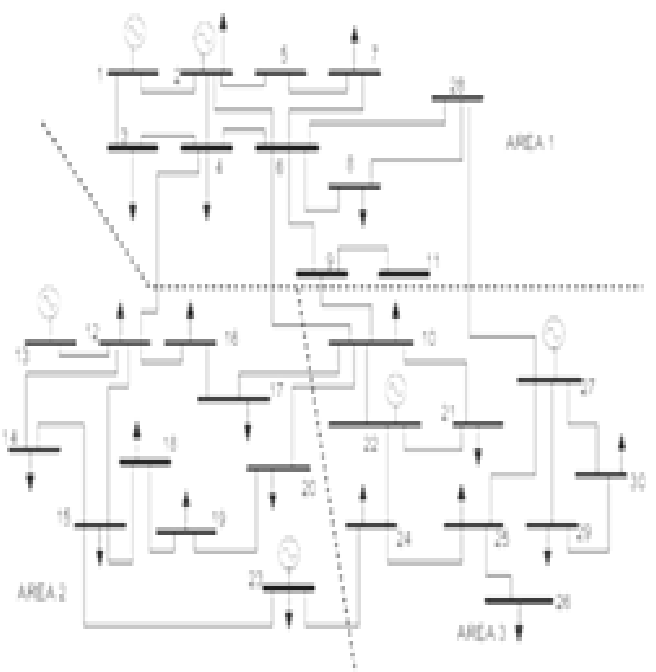


FIG.3: IEEE 30-BUS SYSTEM

\section{Simulation Results and Discussion}

To illustrate the applicability of the proposed method to allocate the FACTS devices in large scale system, a modified IEEE 30 bus system is used. Figure. 3 shows the sample test system. he system is divided into three areas with two generators in each area. And FACTS device allocated to these area for calculation of ATC. In this work, ant colony optimization based algorithm has been proposed for ATC calculation. To verify and validity of the results of the proposed algorithm with a Genetic Algorithm method is prepared as shown in Table I. Two FACTS devices, TCSC and SVC are installed simultaneously in the system in order to enhance ATC. The ACO algorithm and GA could allocate the devices in certain combination of types, rated value and location. The results of the simulation are shown in Table I. The Six cases are studied where the power is transferred from 1 to 2,1 to 3,2 to 1,2 to 3,3 to 1 and 3 to 2.Using the RPF method without FACTS devices, the ATC to transfer the power from Area 1 to area 2 is $50.86 \mathrm{MW}$ and the limiting condition as expected is the generation upper limit at bus 1, PG1, if further transfers take place. When FACT Devices are installed using GA, the ATC to transfer power from Area 1 to Area 2 is increased 52.21 MW and the limiting condition is the upper limit of the same generator, PG1. Using GA, two SVCs need to be placed at line 12-15 with 35.74MVAR and at line 9 to 10 with 59.74MVAR respectively. However, using ACO, the ATC is increased to 52.33MW. The combination changes to one TCSC with rated value of $-28.674 \%$ Xlineat location 6 to 9 and one SVC with size of 74.24MVAR at location 10 to 20.

Results for IEEE-30 bus system

\begin{tabular}{|c|c|c|c|c|c|c|c|c|c|}
\hline \multicolumn{2}{|c|}{ Transfer } & \multicolumn{2}{|c|}{$\begin{array}{l}\text { ATC without } \\
\text { FACTS }\end{array}$} & \multirow{2}{*}{$\begin{array}{l}\text { Allocation } \\
\text { Technique }\end{array}$} & \multicolumn{5}{|c|}{ ATC with FACTS Devices } \\
\hline $\begin{array}{l}\text { From } \\
\text { Area }\end{array}$ & $\begin{array}{l}\text { From } \\
\text { To }\end{array}$ & $\begin{array}{l}\text { ATC } \\
\text { (MW) }\end{array}$ & $\begin{array}{l}\text { Limit } \\
\text { Condition }\end{array}$ & & $\begin{array}{l}\text { Facts } \\
\text { Type }\end{array}$ & $\begin{array}{l}\text { Size } \\
\text { (rated value) }\end{array}$ & Location & $\begin{array}{l}\text { ATC } \\
\text { (MW) }\end{array}$ & $\begin{array}{l}\text { Limit } \\
\text { Conditiol }\end{array}$ \\
\hline \multirow[t]{2}{*}{1} & \multirow[t]{2}{*}{2} & \multirow[t]{2}{*}{50.86} & \multirow[t]{2}{*}{ PG1 } & GA & $\begin{array}{l}\text { SVC } \\
\text { SVC }\end{array}$ & $\begin{array}{l}\text { 35.74MVAR } \\
\text { 59.74MVAR }\end{array}$ & $\begin{array}{l}\text { LINE 12-15 } \\
\text { LINE 9-10 }\end{array}$ & 51.21 & PG1 \\
\hline & & & & $\mathrm{ACO}$ & $\begin{array}{l}\text { TCSC } \\
\text { SVC }\end{array}$ & $\begin{array}{l}-28.64 \% \\
\text { Xline } \\
\text { 74.24MVAR }\end{array}$ & $\begin{array}{l}\text { LINE 6-9 } \\
\text { LINE 10-20 }\end{array}$ & 51.33 & PG1 \\
\hline \multirow[t]{2}{*}{1} & \multirow[t]{2}{*}{3} & \multirow[t]{2}{*}{48.31} & \multirow[t]{2}{*}{ PG22 } & GA & $\begin{array}{l}\text { SVC } \\
\text { SVC }\end{array}$ & $\begin{array}{l}\text { 29.68MVAR } \\
\text { 34.98MVAR }\end{array}$ & $\begin{array}{l}\text { LINE } 8-28 \\
\text { LINE } 10-22\end{array}$ & 50.86 & PG1 \\
\hline & & & & $\mathrm{ACO}$ & $\begin{array}{l}\text { TCSC } \\
\text { SVC }\end{array}$ & $\begin{array}{l}\text {-28.71\%Xline } \\
\text { 65.94MVAR }\end{array}$ & $\begin{array}{l}\text { LINE 6-9 } \\
\text { LINE 10-17 }\end{array}$ & 50.93 & PG1 \\
\hline 2 & 1 & 9.07 & PG23 & GA & $\begin{array}{l}\text { TCSC } \\
\text { SVC }\end{array}$ & $\begin{array}{l}-50.29 \% \text { Xline } \\
\text { 38.3MVAR }\end{array}$ & $\begin{array}{l}\text { LINE 6-9 } \\
\text { LINE 8-28 }\end{array}$ & 9.43 & PG23 \\
\hline
\end{tabular}




\begin{tabular}{|c|c|c|c|c|c|c|c|c|c|}
\hline & & & & $\mathrm{ACO}$ & $\begin{array}{l}\text { TCSC } \\
\text { SVC }\end{array}$ & $\begin{array}{l}-50.11 \% \text { Xline } \\
\text { 32.4MVAR }\end{array}$ & $\begin{array}{l}\text { LINE 6-9 } \\
\text { LINE 8-28 }\end{array}$ & 9.56 & PG23 \\
\hline \multirow[t]{2}{*}{2} & \multirow[t]{2}{*}{3} & \multirow[t]{2}{*}{7.96} & \multirow[t]{2}{*}{ PG23 } & GA & $\begin{array}{l}\text { TCSC } \\
\text { SVC }\end{array}$ & $\begin{array}{l}-47.10 \% \text { Xline } \\
\text { 30.84MVAR }\end{array}$ & $\begin{array}{l}\text { LINE 9-10 } \\
\text { LINE 8-28 }\end{array}$ & 8.49 & PG23 \\
\hline & & & & $\mathrm{ACO}$ & $\begin{array}{l}\text { TCSC } \\
\text { SVC }\end{array}$ & $\begin{array}{l}-45.35 \% \text { Xline } \\
\text { 33.22MVAR }\end{array}$ & $\begin{array}{l}\text { LINE 9-10 } \\
\text { LINE 8-28 }\end{array}$ & 8.50 & PG23 \\
\hline \multirow[t]{2}{*}{3} & \multirow[t]{2}{*}{1} & \multirow[t]{2}{*}{24.81} & \multirow[t]{2}{*}{ PG27 } & GA & $\begin{array}{l}\text { TCSC } \\
\text { SVC }\end{array}$ & $\begin{array}{l}-44.99 \% \text { Xline } \\
\text { 41.82MVAR }\end{array}$ & $\begin{array}{l}\text { LINE } 28-27 \\
\text { LINE 8-28 }\end{array}$ & 25.94 & PG27 \\
\hline & & & & $\mathrm{ACO}$ & $\begin{array}{l}\text { TCSC } \\
\text { SVC }\end{array}$ & $\begin{array}{l}-44.03 \% \text { Xline } \\
\text { 41.08MVAR }\end{array}$ & $\begin{array}{l}\text { LINE } 27-28 \\
\text { LINE } 8-28\end{array}$ & 25.98 & PG27 \\
\hline \multirow[t]{2}{*}{3} & \multirow[t]{2}{*}{2} & \multirow[t]{2}{*}{24.51} & \multirow[t]{2}{*}{ PG27 } & GA & $\begin{array}{l}\text { TCSC } \\
\text { SVC }\end{array}$ & $\begin{array}{l}-53.67 \% \text { Xline } \\
\text { 44.94MVAR }\end{array}$ & $\begin{array}{l}\text { LINE } 27-28 \\
\text { LINE } 8-28\end{array}$ & 25.33 & PG27 \\
\hline & & & & $\mathrm{ACO}$ & $\begin{array}{l}\text { TCSC } \\
\text { SVC }\end{array}$ & $\begin{array}{l}-53.94 \% \text { Xline } \\
\text { 43.86MVAR }\end{array}$ & $\begin{array}{l}\text { LINE } 27-28 \\
\text { LINE } 8-28\end{array}$ & 25.84 & PG27 \\
\hline
\end{tabular}

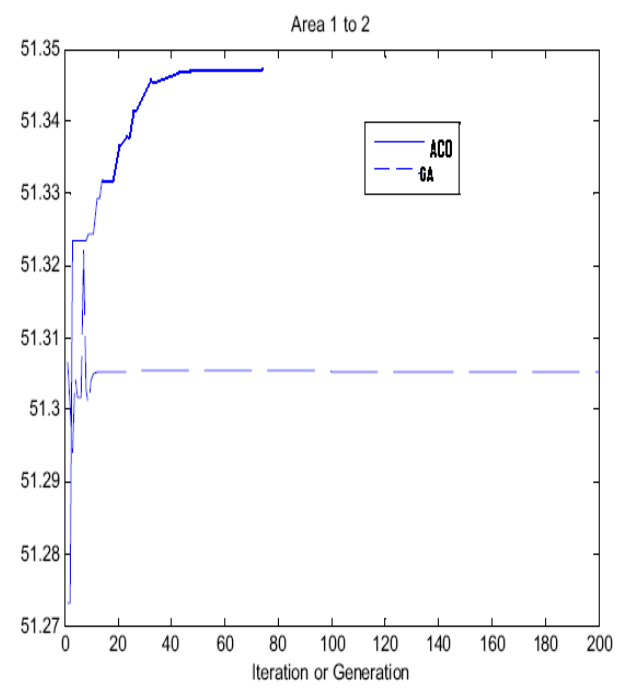

Fig 4: The convergences characteristics of the fitness of the ACO and

\section{GA}

It clearly shown that ACO could effectively allocate the A device as GA does. Moreover ACO could reach the optimum solution 4 times faster than GA for nearly the same results. For all of the cases, ACO could find better location to install the devices to enhance ATC slightly better than GA. Figure 4 shows the comparison of rapid convergences characteristics of the proposed method and GA. For other transfer between different control areas, with and without FACT devices, test results indicate that optimally placed FACTS devices can significantly enhance ATC of the system as shown in Table I

\section{Conclusion}

New optimization algorithm to optimally allocate FACTS devices to enhance ATC. The simulation results tremendously prove that the proposed algorithm has remarkable robustness, in maximizing the 
ATC. Furthermore, the result also shows the effectiveness of the new approach in simultaneously optimized the FACTS location, rated values and FACTS types. It is a practical method for the allocation of FACTS devices in large power system. The Ant colony algorithm converged to the maximum without becoming trapped at local optima. The algorithm generally outperformed the GA techniques that were compared with it in terms of speed of optimization and accuracy of the results obtained. The main advantage of ACO is that it does not require external parameters such as cross over rate and mutation rate etc, as in case of genetic algorithms these are hard to determine in prior. The other advantage is that the global search ability in the algorithm is implemented by introducing neighborhood source production mechanism which is a similar to mutation process. However, one of the drawbacks of the algorithm is the number of tunable parameters used. Nevertheless, it is possible to set the parameter values by conducting a small number of trials. The Program has been developed in Object Oriented Programming (OOP) advanced Java language and the has been tested on latest Core 2 duo processor.

\section{References}

[1] L.L.Feris and A.M. Sasson, "Investigation of Load Flow Problem", Proc IEE, Part-C, Vol.115, 1986,pp.1459-1470.

[2] O. Alsacand B. sttot," Optimal Power Flow with Steady-State Security" IEE Trans on Power Apparatus and Systems, Vol. PAS-93, 1974, pp. 745-751.

[3] B. Stott and E. Hosbon, " Power System Security Control Calculation using Linear ProgrammingPart I', IEEE Trans. On Power Apparatus and System, Vol.PAS-97, 1978, pp. 1713-1719.

[4] G.C.Ejebe and B.F. Wollenberg," Automatic Contingency Selection", IEEE Trans. on Power Apparatus and Systems, Vol.98, No.1 January/February 1979,pp. 92-104.

[5] T.J.E Miller, reactive Power Control in Electrical System, John Wiley \& Sons USA, 1982.

[6] N. Srinivasan, C.S. Indulkar, K.S.P., Rao and S.S. Venkata, "On-line Computation of Phase Shifter

Distribution Factors and Line Load Alleviation" IEEE Trans. on Power Apparatus and Systems, Vol.PAS-104, No.7 ,1985, pp. 1656-1662.

[7] M. C. Caramanis, R.E. Bohn, and E.c. Schweppe, "The Cost Of Wheeling and Optimal Wheeling Rates",IEEE Trans on Power Systems, Vol.1,No.1, 1986.

[8] N.G. Hingorani, "Power Electronics in Electric Utilities: Role of Power Electronics in future power systems" Proc. Of the IEEE, Vol. 76, No.4 April 1988, pp.481-482.

[9] F.C. Scheweppe, M.C. Caramanis, R.D.Tabors, and R.E.Bohn, Spot Pricing of Electricity, Norwell, MA :Kulwer, 1988.

[10] P.W. sauer and M.A.Pai," Power System Steady State Stability and the Load Flow Jacobian”, IEEE Trans. On Power Systems, Vol.5, No.4 Nov.1990, pp. 1374-1382.

[11] M.L. Baughman and S.N. Siddiqi, "Real-Time Pricing of Reactive Power: Theory and Case Study Results”. IEEETrans on Power Systems, Vol.6, No.1, February1991,pp.23-29.

[12] V.Ajjarapu and C. Christy, "The Continuation Power Flow: A Tool for Steady State Voltage Stability Analysis", IEEE Trans. on Power System, Vol.7,February 1992, pp. 416-423.

[13] L. Gyugyi, "A Unified Power Flow Concept for Flexible AC Transmission Systems", IEE Proceedings on Generation, Transmission, Distribution, Part-C, Vol.139, No.4 July 1992, pp.323331.

[14]W.W.Hogan, “Contract Network for Electric Power Transmission,”J.Regul Econ,Vol.4,Sept 1992,pp.211-242.

[15] K.G. Upadhyay, S.N. Singh, D.S. Chuahan, and G. S. Srivastava, 'Wheeling ....... And Pricing Mechanism: An Overview and Key Issues', Proc. International' Conference on Computer Application in Electrical Engineering (CER......) University of Roorkee, India, 2002, pp. 133-144. 
[16] X. Wang, Y. H. Song, Q. Lu, and Y.Z. Sun, "Optimal Allocation of Transmission .Rights in Systems with FACTS Devices", IEE Proc. On Generation, Transmission, and Distribution, Vol. 149, No. 3, May 2002, pp. 359-366.

[17] F.G.M. Lima, J. Munoz, I. Kockar, and F.D, Galiana, "Optimal Location of Phase Shifters in a Competitive Market by Mixed Integer Linear Programming”, Proc. of $14^{\text {th }}$ PSCC, Spain, June 2428, 2002.

[18] M.V. Cazzol, A. Garzillo, M. Innorta, M.G. Libardi and M. Ricci, "Unified Power Flow Controller (UPFC) Model in the Framework of Inerior Point based Active and Reactive OPF Procedure", International Journal of Electrical Power and Energy Systems, Volume 24, Issue 6, August 2002, pp. 431-437.

[19]Kwang-Ho-Lee, "Optional Siting of TCSC for Reducing Congestion Cost by using Shadow Prices", Electrical Power and Energy Systems, Volume 24, Oct. 2002, pp. 647-653.

[20]BalkascemMehdad, TarekBourktir, KamelSrairi, "Flexible Methodology based in Fuzzy Logic Rules for Reactive Power Planning of Multiple Shunt FACTS Devices to Enhance system Loadability", Proc.PES General Meeting, 24-28 Jun 2007.

[21] G.Yesurantnam and D. Thukaram, "Congestion Management in Open Access Based on Relative Electrical Distances using Voltage stability Criteria", Electric Power System research Vol. 77, Issue 12, October 2007, pp.1608-1610.

[22] Roberto Minguez,Federico Milano, Rafael Zarate-Minano and Antonio J. Conjeo, "Optimal Network Placement of SVC Devices”, IEETrans. On Power System,Vol.22, No.4 Nov.2007,pp. 1851-1860. 